\title{
Silver Materials Induce Differential Cytotoxicity and Pulmonary Toxicity Based on Size and Shape
}

\author{
Pyo June Pak - Beob Hwa Kang • Namhyun Chung*
}

Received: 29 January 2015 / Accepted: 4 February 2015 / Published Online: 30 June 2015

(C) The Korean Society for Applied Biological Chemistry 2015

\begin{abstract}
Silver materials may be toxic in humans because they can enter the body and accumulate, typically in the lungs. We hypothesized that the cytotoxicity of naïve silver materials is affected by their size and shape. Our in vitro assays revealed that the overall toxicity was in the following order: submicro-particles $>$ wires $>$ micro-particles. These results contrast with previous studies, which showed that silver wires are the most toxic among the three tested materials, possibly due to differences in cell lines. Evaluations of in vivo pulmonary toxicity revealed eryptosis in the cavity lining of the lung sections. The observed eryptosis was consistent with the in vitro results. Our results indicate that silver materialinduced cytotoxicity must be measured and compared using various methods.
\end{abstract}

Keywords cytochalasin $\mathrm{D} \cdot$ in vitro toxicity $\cdot$ pulmonary toxicity - silver materials $\cdot$ silver wire

With the rapid advancement of nanotechnology and its applications, many nanomaterials are now used in a wide variety of industries (Panyala et al., 2008; Wijnhoven et al., 2009; Sohaebuddin et al., 2010). However, engineered nanomaterials have unique physical (size, shape, surface charge) and chemical (coating agent, dispersion, electronicity, and magneticity) attributes, which can cause unpredictable effects on health (Chithrani et al., 2006; Carlson et al., 2008; Matzke et al., 2014; Silva et al., 2014). Silver materials, which are often micro- or nanoparticles, are widely known to have

P. J. Pak $\cdot$ B. H. Kang $\cdot$ N. Chung

Department of Biosystems Engineering, College of Life Sciences and Biotechnology, Korea University, Seoul 136-712, Republic of Korea

*Corresponding author (N. Chung: nchung@korea.ac.kr)

This is an Open Access article distributed under the terms of the Creative Commons Attribution Non-Commercial License (http://creativecommons. org/licenses/by-nc/3.0/) which permits unrestricted non-commercial use, distribution, and reproduction in any medium, provided the original work is properly cited. powerful antibacterial activity. Thus, the use of silver materials in bactericidal products has increased (Blaser et al., 2008). However, in some silver products, the potential risks of these materials have become prevalent (Wijnhoven et al., 2009). As the size of these materials decreases, their risks increase, due to increased hydrogen peroxide production (Batchelor-McAuley et al., 2014). Thus, the effects of particle size, surface charge, coating for dispersion, and concentrations in nanoscale $(1-100 \mathrm{~nm})$ on environmental toxicity has been evaluated (Batchelor-McAuley et al., 2014; Matzke et al., 2014; Silva et al., 2014). Several reports have sought to correlate the shape of various materials with toxicity (Jung et al., 2014; Kim et al., 2014; Lee et al., 2014). Nevertheless, the relationship between cytotoxicity and material shape remains unclear. Thus, we investigated the pulmonary toxicity of naïve silver materials based on their size and shape.

We employed three types of silver material. Silver micro-particles (AgMPs), silver submicro-particles (AgSMPs), and silver wires (AgWs) were purchased from Sigma-Aldrich (USA), Nano Technology Inc. (Korea), and NanoAmor (USA), respectively. The characterization and preparation of the silver materials were reported in our previous study (Jung et al., 2014). The dimensions of the silver materials were $2.7 \mu \mathrm{m}$ (diameter), $150 \mathrm{~nm}$ (diameter), and $274 \mathrm{~nm}$ (diameter) $\times 5.3 \mu \mathrm{m}$ (length) for AgMPs, AgSMPs, and $\mathrm{AgWs}$, respectively. A silver material stock solution $(2 \mathrm{mg} /$ $\mathrm{mL}$ ) was prepared in Dulbecco's Modified Eagle's Medium (DMEM) (WelGene, Korea) and sonicated for $3 \mathrm{~min}$. The stock solution was diluted to working solutions $(25,50,100$, and 200 $\mu \mathrm{g} / \mathrm{mL}$ ) and re-sonicated prior to use. The murine macrophage cell line (RAW264.7; KCLB No. 40071) was purchased from the Korean Cell Line Bank (KCLB). Cells were seeded at equal density $\left(5 \times 10^{5}\right.$ cells $\left./ \mathrm{mL}\right)$ for all experiments and grown for $24 \mathrm{~h}$. The cells were then treated with silver materials for $24 \mathrm{~h}$. After treatment, cell viability was evaluated by trypan blue exclusion assay. The cell number was counted with a hemocytometer after harvesting. Reactive oxygen species (ROS) generation in the presence of silver materials was measured by staining the cells with 2',7,-dichlorofluorescein-diacetate (DCFH-DA). The degree of silver material-induced inflammation and cytotoxicity was 

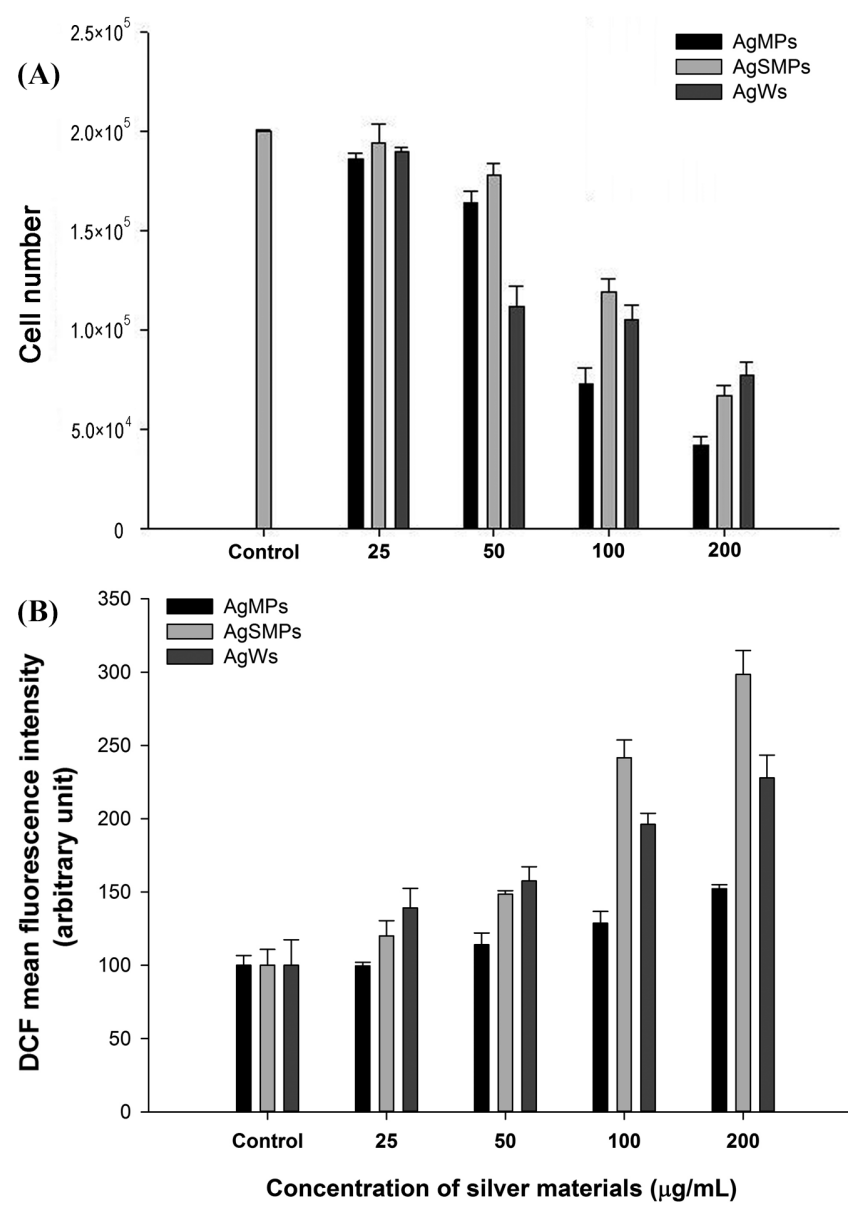

Fig. 1 Changes in the extent of cell viability and ROS generation at various silver material concentrations. Cell viability was measured by trypan blue exclusion (A). After treatment with silver materials for $24 \mathrm{~h}$, cells were stained with DCFH-DA for $30 \mathrm{~min}$, and the fluorescence intensity was measured by fluorometer (B). Data represent the mean \pm $\operatorname{SD}(n=3)$.

evaluated by measuring the production of tumor necrosis factor (TNF)- $\alpha$ using an enzyme-linked immunosorbent assay (ELISA; R\&D System, USA). Membrane rupture was measured using a lactate dehydrogenase (LDH) cytotoxicity detection kit (Takara Inc., Japan) according to the manufacturer's protocol. For the TNF- $\alpha$ and LDH studies, the cells were treated with an actin depolymerizing agent (cytochalasin $\mathrm{D}$; phagocytosis and phagolysosome fusion inhibitor) during cell attachment.

Finally, we examined the toxicity of silver materials in an animal model. Seven-week-old, female BALB/c mice were purchased from Orient Bio Inc. (Korea). All animals were maintained in conventional condition under a $12 \mathrm{~h}$ light/dark cycle. After acclimatization for 1 week, 12 mice were randomly divided into four groups as follows: control (DMEM), treatment with AgMPs $(100 \mu \mathrm{g} / \mathrm{mL})$, treatment with AgSMPs $(100 \mu \mathrm{g} / \mathrm{mL})$, and treatment with AgWs $(100 \mu \mathrm{g} / \mathrm{mL})$. Mice were intratracheally administered $200 \mu \mathrm{L}$ working solution and sacrificed after $24 \mathrm{~h}$. Lungs were fixed in $4 \%$ paraformaldehyde for histological analyses. Paraffin- embedded sections were stained with hematoxylin and eosin (H\&E) to observe histological injury using an Olympus CK40 microscope (Olympus, Japan). All protocols for animal use and euthanasia were in accordance with the National Institutes of Health guidelines and approved by the Korea University Institutional Animal Care and Use Committee.

We studied the invasion of silver materials from the environment into the cell. Thus, we employed naïve silver materials so that capping agents were not used for dispersion. The dispersion force of silver materials was shown by zeta potential analysis in our previous study (Jung et al., 2014). The zeta potential of silver materials was less than $-40 \mathrm{mV}$. To estimate the cytotoxicity of silver materials, we evaluated the cell number (Fig. 1A). As the silver material concentration increased, the cell number decreased, with AgMPs having the greatest effect. When cell viability was measured using LDH leakage, cytotoxicity was higher when using AgMPs and AgSMPs than when using AgWs (Fig. 2A). These results indicate that the cytotoxicity of silver materials is not affected by the shape of the material, meaning that $\mathrm{AgWs}$ often have a much lower cytotoxicity than the other two materials in the present exepriment. This is in contrast to our previous results, which indicated that $\mathrm{AgW}$-induced cytotoxicity was higher than that induced by the other silver materials (Jung et al., 2014). These findings also show that the relative silver material-induced cytotoxicity is dependent on the method used to measure cytotoxicity.

In general, silver materials are in an ionic form (Panyala et al., 2008). These silver ions play a critical role in the toxicity of silver materials (Beer et al., 2012). Ahamed et al. (2010) and AshaRani et al. (2009) showed that Ag-induced ROS generation is a major cause of toxicity. Therefore, we confirmed ROS generation in the presence of the three silver materials (Fig. 1B). As the silver material concentration increased, the overall extent of ROS generation increased. The amount of ROS production was as follows: AgSMPs $>\mathrm{AgWs}>\mathrm{AgMPs}$. Batchelor-McAuley et al. (2014) showed that silver nanoparticles are more toxic than bulk silver, due to the increased effective hydrogen peroxide concentration with silver particles less than $1 \mu \mathrm{m}$. Our results are consistent with this data because AgSMPs have a diameter of $150 \mathrm{~nm}$. Our previous study showed that the extent of ROS generation with $\mathrm{AgWs}$ is the highest among the tested silver materials. We hypothesized that this effect was due to the rod shape of the AgWs, resulting in the largest surface area (Jung et al., 2014). However, these data were obtained in THP-1 cells (human acute monocytic leukemia cell line), which differed from the RAW 264.7 cells (murine macrophage cell line) in the present study.

We observed general cytotoxicity with the three different types of silver materials. We next evaluated whether silver-induced cytotoxicity was affected by the suppression of phagocytosis. The interaction of metallic particles with mammalian cells depends on their size and shapes (Carlson et al., 2008). Thus, the extent of LDH leakage (Fig. 2A) and TNF- $\alpha$ production (Fig. 2B) was measured in the presence or absence of cytochalasin $\mathrm{D}$. When phagocytosis was inhibited by cytochalasin $\mathrm{D}$, the extent of LDH leakage decreased significantly in all treated groups. These 

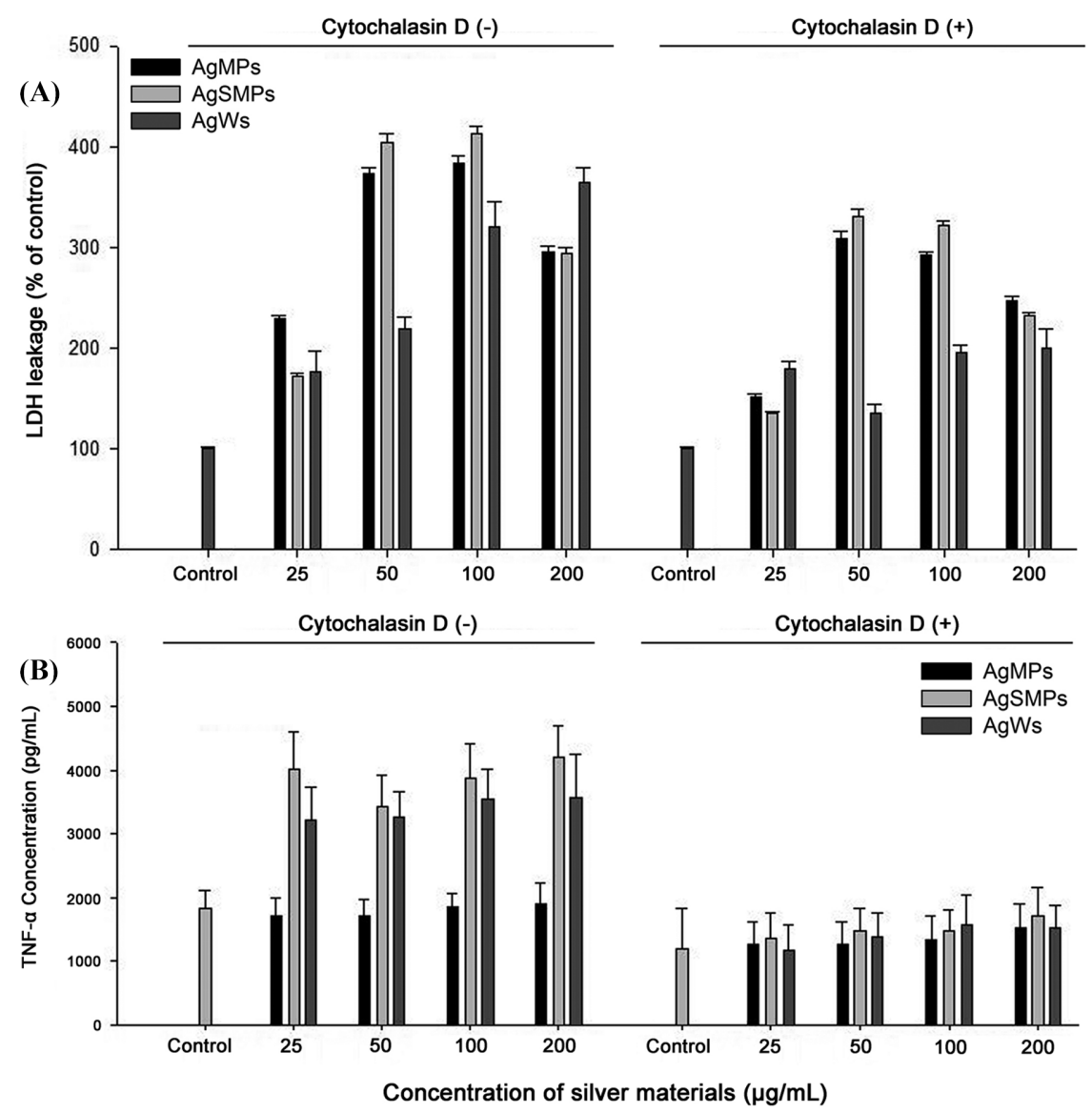

Fig. 2 Changes in the extent of LDH leakage and TNF- $\alpha$ production in the presence or absence of the phagocytosis inhibitor, cytochalasin D. LDH leakage was measured by an LDH Cytotoxicity Detection Kit (A). The production of TNF- $\alpha$ was mesured by ELISA (B). Cells were treated with Cytochalasin D before silver material treatment. Data represent the mean $\pm \mathrm{SD}(\mathrm{n}=3)$.

(A)

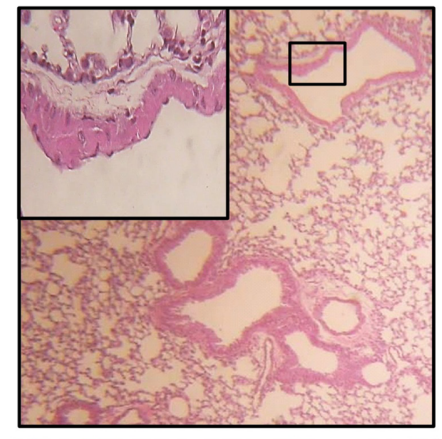

(C)

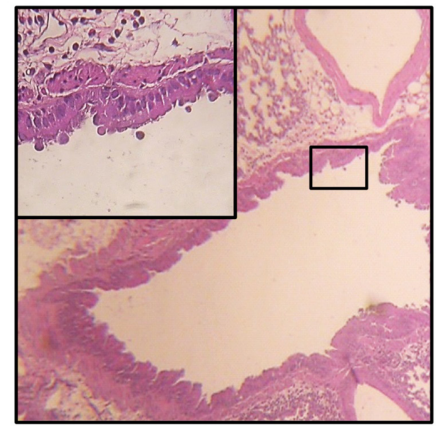

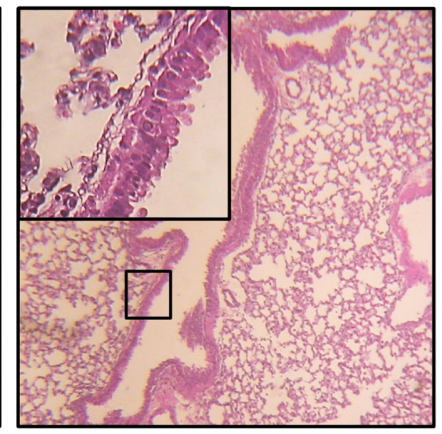

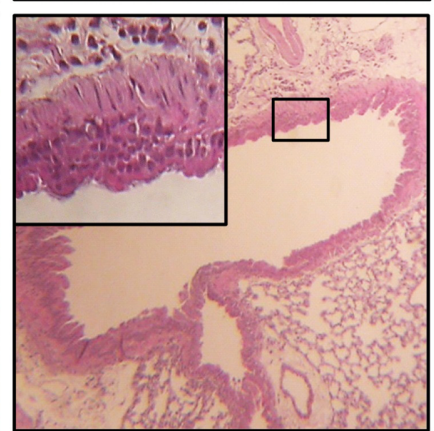

(B)

(D)

Fig. 3 Histological differences after silver material treatment in vivo. Lung tissue sections were stained with H\&E; control (A) AgSMPs (B) AgMPs (C) $\mathrm{AgWs}$ (D). 
findings suggest that silver materials enter cells by phagocytosis, as was observed in THP-1 cells. Thus, the shape of silver materials may not be a factor in cytotoxicity in RAW264.7 cells. AgMPs had no effect on TNF- $\alpha$ production; however, TNF- $\alpha$ production was increased by AgSMPs and AgWs. Interestingly, this increase was not affected by changes in concentration. When phagocytosis was inhibited by cytochalasin D, the increase in TNF- $\alpha$ concentration was abolished (Fig. 2). Thus, our data showed that the cytotoxicity measured using LDH leakage and TNF- $\alpha$ production was correlated with phagocytosis. However, in our previous study, the higher degree of cytotoxicity with AgWs, as compared to AgSMPs and AgMPs, was not observed, possibly due to the different characteristics of the cell lines.

We hypothesized that the in vitro cytotoxicity of silver materials would be observed with the respiratory organs of an animal model. The respiratory system plays a role in the entrance or exit of silver materials larger than nanoparticles (Panyala et al., 2008). Although respiratory organs are stained by inhaled silver materials, this staining is not harmful to human health (Song et al., 2009). After contamination or staining with silver materials, paraffinembedded lung sections were evaluated using H\&E stain. As expected, following silver material treatment, suicidal erythrocyte death, or eryptosis (Lang et al., 2008), was detected in the cavities lining the lung sections. The extent of erythrocyte eryptosis was equal in AgSMPs and AgWs, and lower in AgMPs (Fig. 3). This observation is similar to the in vitro ROS generation results (Fig. 1B). These data indicate that silver materials induce pulmonary toxicity in respiratory organs by inducing necrotic cell death and erythrocyte eryptosis.

In this study, we evaluated three types of naive silver materials to compare cytotoxicity. The potential toxicity of silver materials in the environment is dependent on the release rate of silver ions from silver materials (Wijnhoven et al., 2009). Insoluble metallic silver is well known to be a minimal health risk (Drake and Hazelwood, 2005). However, metallic silver can be toxic, depending on the size and shape. Silver materials are widely used in a variety of applications, and humans can be exposed through various portals of entry. Nevertheless, the clearance of silver materials in body is not a trivial process. Larger silver materials are more difficult to excrete from the body (Drake and Hazelwood, 2005). Due to this fact, it is necessary to emphasize safety in workplace, where most exposure could occur. More information regarding the contribution of size, shape, surface charge, and capsulating agent to toxicity is necessary. Moreover additional methods of toxicity measurement are necessary. This information will help create new paradigms in silver-induced toxicity, allowing for improved usage of silver materials. Our current findings and previous studies contribute to the comprehensive studies of silver-induced toxicity.

Acknowledgments This work was supported by a grant from the National Research Foundation of Korea (NRF-2011-0017012) and a Korea University Grant.

\section{References}

Ahamed M, AlSalhi MS, and Siddiqui MKJ (2010) Silver nanoparticle applications and human health. Clinica Chimica Acta 411(23-24), 18418.

AshaRani PV, Mun GLK, Hande MP, and Valiyaveettil S (2009) Cytotoxicity and genotoxicity of silver nanoparticles in human cells. Acs Nano 3(2), 279-90.

Batchelor-McAuley C, Tschulik K, Neumann CCM, Laborda E, and Compton RG (2014) Why are silver nanoparticles more toxic than bulk silver? Towards understanding the dissolution and toxicity of silver nanoparticles. Int J Electrochem Sci 9(3), 1132-8.

Beer C, Foldbjerg R, Hayashi Y, Sutherland DS, and Autrup H (2012) Toxicity of silver nanoparticles-Nanoparticle or silver ion? Toxicol Lett 208(3), 286-92.

Blaser SA, Scheringer M, MacLeod M, and Hungerbuhler K (2008) Estimation of cumulative aquatic exposure and risk due to silver: Contribution of nano-functionalized plastics and textiles. Sci Total Environ 390(2-3), 396-409.

Carlson C, Hussain SM, Schrand AM, Braydich-Stolle LK, Hess KL, Jones RL et al. (2008) Unique cellular interaction of silver nanoparticles: Sizedependent generation of reactive oxygen species. J Phys Chem B 112(43), 13608-19.

Chithrani BD, Ghazani AA, and Chan WCW (2006) Determining the size and shape dependence of gold nanoparticle uptake into mammalian cells. Nano Lett 6(4), 662-8.

Drake PL and Hazelwood KJ (2005) Exposure-related health effects of silver and silver compounds: a review. Ann Occup Hyg 49(7), 575-85.

Jung HJ, Pak PJ, Park SH, Ju JE, Kim JS, Lee HS et al. (2014) Silver wire amplifies the signaling mechanism for IL-1beta production more than silver submicroparticles in human monocytic THP-1 cells. Plos One 9(11), e112256. doi: 10.1371/journal.pone.0112256.

Kim BI, Joo YH, Pak PJ, Kim JS, and Chung N (2014) Different shapes of $\mathrm{Al}_{2} \mathrm{O}_{3}$ particles induce differential cytotoxicity via a mechanism involving lysosomal destabilization and reactive oxygen species generation. $J$ Korean Soc Appl Biol Chem (In Press). doi: 10.1007/s13765-015-0038-6.

Lang F, Gulbins E, Lerche H, Huber SM, Kempe DS, and Foller M (2008) Eryptosis, a window to systemic disease. Cell Physiol Biochem 22(5-6), 373-80.

Lee JH, Ju JE, Kim BI, Pak PJ, Choi EK, Lee HS et al. (2014) Rod-shaped iron oxide nanoparticles are more toxic than sphere-shaped nanoparticles to murine macrophage cells. Environ Toxicol Chem 33: 2759-66.

Matzke M, Jurkschat K, and Backhaus T (2014) Toxicity of differently sized and coated silver nanoparticles to the bacterium Pseudomonas putida: risks for the aquatic environment? Ecotoxicology, 23(5), 818-29.

Panyala NR, Pena-Mendez EM, and Havel J (2008) Silver or silver nanoparticles: a hazardous threat to the environment and human health? J Appl Biomed 6(3), 117-29.

Silva T, Pokhrel LR, Dubey B, Tolaymat TM, Maier KJ, and Liu XF (2014) Particle size, surface charge and concentration dependent ecotoxicity of three organo-coated silver nanoparticles: Comparison between general linear model-predicted and observed toxicity. Sci Total Environ 468, 968-76.

Sohaebuddin SK, Thevenot PT, Baker D, Eaton JW, and Tang LP (2010) Nanomaterial cytotoxicity is composition, size, and cell type dependent. Part Fibre Toxicol 7, 22.

Song Y, Li X, and Du X (2009) Exposure to nanoparticles is related to pleural effusion, pulmonary fibrosis and granuloma. Eur Respir J 34(3), 559-67.

Wijnhoven SWP, Peijnenburg WJGM, Herberts CA, Hagens WI, Oomen AG, Heugens EHW et al. (2009) Nano-silver - a review of available data and knowledge gaps in human and environmental risk assessment. Nanotoxicology 3(2), 109-38 